\title{
Altered Stress-Induced Anxiety in Adenylyl Cyclase Type VIII- Deficient Mice
}

\author{
Michele L. Schaefer, ${ }^{1}$ Scott T. Wong, ${ }^{2}$ David F. Wozniak, ${ }^{3}$ Lisa M. Muglia, ${ }^{1}$ Jason A. Liauw, ${ }^{4}$ Min Zhuo, ${ }^{4}$ \\ Anthony Nardi, ${ }^{3}$ Richard E. Hartman, ${ }^{3}$ Sherri K. Vogt, ${ }^{1}$ Christina E. Luedke, ${ }^{6}$ Daniel R. Storm, ${ }^{2}$ and \\ Louis J. Muglia ${ }^{1,5}$ \\ Departments of ${ }^{1}$ Pediatrics, ${ }^{3}$ Psychiatry, ${ }^{4}$ Anesthesiology and Anatomy and Neurobiology, and 5 Molecular Biology and \\ Pharmacology and Obstetrics and Gynecology, Washington University School of Medicine, St. Louis, Missouri 63110, \\ 2Department of Pharmacology, University of Washington, Seattle, Washington 98195, and ${ }^{6}$ Division of Endocrinology, \\ Children's Hospital, Boston, Massachusetts 02115
}

Stress results in alterations in behavior and physiology that can be either adaptive or maladaptive. To define the molecular pathways involved in the response to stress further, we generated mice deficient $(\mathrm{KO})$ in the calcium-stimulated adenylyl cyclase type VIII (AC8) by homologous recombination in embryonic stem cells. AC8 KO mice demonstrate a compromise in calcium-stimulated $A C$ activity in the hippocampus, hypothalamus, thalamus, and brainstem. Hippocampal slices derived from AC8 KO mice fail to demonstrate CA1-region long-term depression after low-frequency stimulation, and AC8 KO mice also fail to activate CRE-binding protein in the $\mathrm{CA} 1$ region after restraint stress. To define the behavioral consequences of AC8 deficiency, we evaluated AC8 KO mice in the elevated plusmaze and open field. Although naïve AC8 KO mice exhibit indices of anxiety comparable with that of wild-type mice, AC8 $\mathrm{KO}$ mice do not show normal increases in behavioral markers of anxiety when subjected to repeated stress such as repetitive testing in the plus-maze or restraint preceding plus-maze testing. These results demonstrate a novel role for AC8 in the modulation of anxiety.

Key words: adenylyl cyclase; cAMP response elementbinding protein; hippocampus; knock-out mice; long-term depression; plus-maze
Stress has been implicated in the precipitation of common human diseases including major depression, alcohol abuse, and cardiovascular disease (McEwen and Stellar, 1993; McEwen, 1998b). Adaptations the body undergoes during stress to maintain stability are critical for survival and incorporate neural, neuroendocrine, and autonomic nervous system pathways (Chrousos and Gold, 1992; Chrousos, 1995). Although acute activation of the adaptive response during stress increases arousal and alters metabolism to restore homeostasis, repeated or aberrant activation of this response may instead worsen medical and psychiatric diseases (McEwen, 1998a). Understanding the molecular mechanisms involved in the response to stress is essential for the design of efficacious therapeutic agents.

Several mediators of the stress response have been characterized. These include corticotropin-releasing hormone and arginine vasopressin synthesized within the hypothalamic paraventricular nucleus that augment adrenal glucocorticoid production and catecholamines from both CNS and peripheral nervous system sources (Chrousos and Gold, 1992; Chrousos, 1995; Sawchenko et

Received Feb. 23, 2000; revised April 11, 2000; accepted April 12, 2000.

This work was supported by grants from the National Institutes of Health, Howard Hughes Medical Institutes, and Monsanto Company and a Burroughs Wellcome Fund Career Development Award in the Biomedical Sciences to L.J.M, a grant from the Alzheimer's Disease Research Center at Washington University School of Medicine to M.Z., and National Institutes of Health Grant NS 20498 to D.R.S. We thank Drs. A. Imamura and G. Gurtner for assistance with experiments and Drs. J. Gitlin and D. Pfaff for helpful discussions.

Correspondence should be addressed to Dr. Louis J. Muglia, Washington University School of Medicine, One Children's Place, Box 8116, St. Louis, MO 63110. E-mail: Muglia L@kids.wustl.edu.

M.L. Schaefer's present address: Neurosciences Program, University of Colorado Health Sciences Center, Denver, CO 80262.

Copyright (C) 2000 Society for Neuroscience $\quad 0270-6474 / 00 / 204809-12 \$ 15.00 / 0$ al., 1996). Corticotropin-releasing hormone (Potter et al., 1994; Smith et al., 1998), serotonin (Ramboz et al., 1998; Grailhe et al., 1999), and glucocorticoid receptor-dependent (Tronche et al., 1999) signaling pathways have also been implicated in the behavioral responses to acute stress. Additionally, an alteration in synaptic transmission efficiency after stress, specifically long-term depression (LTD) in the CA1 region of the hippocampus, may play a role in stress-dependent learning (Kim et al., 1996; Xu et al., 1997; Manahan-Vaughan and Braunewell, 1999). Hippocampal LTD has been associated with cAMP and protein kinase A (Brandon et al., 1995) and glucocorticoid (Xu et al., 1998) signaling pathways, although the importance of LTD in modifying stress-related behavior has not been established.

Production of cAMP by adenylyl cyclase (AC) provides an important mechanism for the regulation of neuronal physiology. The calcium-stimulated AC isoforms have been strongly implicated in the alteration of neuronal function based on previous stimulation (Cooper et al., 1995; Sunahara et al., 1996). Targeted inactivation of the calcium-stimulated AC type I (AC1) results in defective spatial learning (Wu et al., 1995), motor coordination (Storm et al., 1998), and hippocampal (Wu et al., 1995) and cerebellar long-term potentiation (Storm et al., 1998). We initiated characterization of AC type VIII (AC8) because of its possible role in the stress response. Like AC1, AC8 undergoes robust stimulation by calcium and calmodulin and would be anticipated to impart plasticity in neuronal responses in a stimulus-dependent manner (Cali et al., 1994). Unlike AC1, AC8 is expressed at high levels in the thalamus, habenula, and hypothalamic paraventricular nucleus, sites involved in the neuroendocrine and behavioral responses to stress, and in the olfactory 
bulb (Xia et al., 1991; Matsuoka et al., 1994; Muglia et al., 1999). Within the hippocampus, AC8 mRNA is expressed primarily in the CA1 region (Muglia et al., 1999), whereas AC1 is robustly expressed in the dentate gyrus and less so in the CA1 region (Xia et al., 1991).

We hypothesized that inactivation of AC8 would result in abnormal behavioral and/or adrenal responses to psychological stressors. In the current study, we test this hypothesis by generating AC8-deficient (KO) mice and examining their responses to acute and chronic stress.

\section{MATERIALS AND METHODS Generation of AC8 KO mice}

To generate a null AC8 allele, we ligated the $4.4 \mathrm{~kb} B a m \mathrm{HI}-X b a \mathrm{I}$ (excised from pBluescript SK II as KpnI-XbaI) fragment from the 5 '-flanking region of the AC8 gene into KpnI- and $X b a \mathrm{I}$-digested pPNT (Tybulewicz et al., 1991). This vector, designated 4.4AC8pPNT, was subsequently digested with $N o t \mathrm{I}$ and $X h o \mathrm{I}$ and ligated to a $5.5 \mathrm{~kb}$ HindIII (excised from pBluescript SK II as NotI-XhoI) fragment distal to exon 1. Introduction of the linearized targeting vector into R1 $(129 / \mathrm{Sv} \times 129 /$ Sv-CP)F1 ES cells (Nagy et al., 1993) resulted in 1 correctly targeted clone out of 150, as determined by Southern blot analysis of ES DNA using a probe external to the targeting vector, after selection with G418 and gancyclovir as described previously (Muglia et al., 1994). Injection of the ES clone 3D6 into C57BL/6 blastocysts resulted in the production of several male chimeras that transmitted the mutant allele through their germline.

\section{Animal husbandry}

To demonstrate germline transmission of the null AC8 allele, chimeric males were mated with outbred Black Swiss females (Taconic, Germantown, NY). Agouti pups heterozygous for the mutated allele were bred to generate homozygous-deficient mice and wild-type (WT) controls of the same genetic background (mixed 129/Sv $\times$ Black Swiss) for the following experiments, as well as heterozygotes for subsequent strain propagation. The mice used in these studies (generations F2-F4) were housed on a 12 $\mathrm{hr}: 12 \mathrm{hr}$ light/dark cycle with rodent chow available ad libitum. All mouse protocols were in accordance with National Institutes of Health guidelines and were approved by the Animal Care and Use Committee of Washington University School of Medicine.

\section{Reverse transcription-PCR analysis}

Two micrograms of total hypothalamic or hippocampal RNA were subjected to reverse transcription (RT)-PCR analysis, with amplification conditions for all primer pairs as described previously (Muglia et al., 1999). The sense primer (AD8-f2) of the 5' primer pair was encompassed by the region deleted in our targeting vector. We therefore generated an intron-spanning primer pair that amplifies a 421 base region from the $3^{\prime}$ end of the AC8 mRNA not deleted during targeting (MSR, 5'-CTACGACCTTGTCTGCTCAG-3'; MAR, 5'-CTCTTCCACGTTATAGTCAC- $3^{\prime}$ ). Intron-spanning primers from the mouse vasopressin gene were included as a control for hypothalamic RNA integrity.

\section{Measurement of calcium-stimulated AC activity}

Excised brain regions from 12- to 14-week-old male AC8 KO and WT mice were suspended in buffer A (20 mM Tris- $\mathrm{HCl}$, pH 7.4, $2 \mathrm{mM} \mathrm{MgCl}_{2}$, $1 \mathrm{~mm}$ EDTA, $0.5 \mathrm{~mm}$ dithiothreitol, $5 \mu \mathrm{g} / \mathrm{ml}$ leupeptin, and $0.5 \mathrm{~mm}$ phenylmethanesulfonyl chloride) and broken at $4^{\circ} \mathrm{C}$ with a Dounce homogenizer. Cell homogenates were centrifuged at $600 \times g$ for $2 \mathrm{~min}$, and the resulting supernatants were centrifuged at $30,000 \times g$ for $20 \mathrm{~min}$. We assayed the resulting membranes for AC activity. The enzyme assay was performed at $30^{\circ} \mathrm{C}$ for $25 \mathrm{~min}$ by adding membrane preparations $(10-15 \mathrm{mg} / \mathrm{ml}$ of protein) to an assay cocktail containing $1 \mathrm{~mm}$ $\left[\alpha-{ }^{32} \mathrm{P}\right]$ ATP $(500 \mathrm{cpm} / \mathrm{pmol}),\left[{ }^{3} \mathrm{H}\right] \mathrm{cAMP}(15,000 \mathrm{cpm} / \mathrm{mmol}), 5 \mathrm{~mm}$ $\mathrm{MgCl}_{2}, 0.2 \mathrm{~mm}$ EGTA, $1 \mathrm{~mm}$ EDTA, $2 \mathrm{~mm}$ cAMP, $5 \mathrm{~mm}$ theophylline, $5 \%$ bovine serum albumin, $20 \mathrm{~mm}$ creatine phosphate, and $100 \mathrm{U} / \mathrm{ml}$ creatine phosphokinase in $20 \mathrm{~mm}$ Tris- $\mathrm{HCl}, \mathrm{pH} 7.4$, in a final assay volume of $250 \mu \mathrm{l}$. The reaction was stopped by adding $750 \mu \mathrm{l}$ of $1.5 \%$ SDS. The reaction mixture was heated at $100^{\circ} \mathrm{C}$ for $2 \mathrm{~min}$, and the $\left[{ }^{32} \mathrm{P}\right] \mathrm{cAMP}$ generated was recovered by using Dowex AG-50 WX-4 and neutral alumina columns, as described (Salomon et al., 1974). Free $\mathrm{Ca}^{2+}$ concentrations were calculated by using the Bound and Determined computer algorithm (Brooks and Storey, 1992). AC activity levels were the means of triplicate determinations. Protein concentrations in the cell membranes were determined by the method of Hill and Straka (1988).

\section{In situ hybridization}

Paraformaldehyde-fixed brains from 8-week-old male AC8 KO and WT mice were cut into $10 \mu \mathrm{m}$ sections and hybridized with a probe specific for AC8 as described previously (Muglia et al., 1999). Adjacent sections were hybridized with an $\left[\alpha^{-}{ }^{33} \mathrm{P}\right] \mathrm{UTP}$-labeled RNA probe to AC1 that detected nucleotides 1557-1955 of the mouse AC1 mRNA (GenBank accession number AF053980). After hybridization and washing, sections were exposed to Hyperfilm $\beta$-max for 5-14 d.

\section{Hippocampal electrophysiology}

Male WT and AC8 KO mice at 6-8 weeks of age were anesthetized with halothane. Transverse slices of hippocampus were rapidly prepared and maintained in an interface chamber at $28^{\circ} \mathrm{C}$, where they were subf used with artificial CSF (ACSF) consisting of $124 \mathrm{~mm} \mathrm{NaCl}, 4.4 \mathrm{~mm} \mathrm{KCl}, 2.0$ $\mathrm{mm} \mathrm{CaCl}_{2}, 1.0 \mathrm{~mm} \mathrm{MgSO}_{4}, 25 \mathrm{~mm} \mathrm{NaHCO}, 1.0 \mathrm{mM} \mathrm{Na}_{2} \mathrm{HPO}_{4}$, and 10 $\mathrm{mm}$ glucose, bubbled with $95 \% \mathrm{O}_{2}$ and $5 \% \mathrm{CO}_{2}$. Slices were kept in the recording chamber for at least $2 \mathrm{hr}$ before the experiments. A bipolar tungsten-stimulating electrode was placed in the stratum radiatum in the CA1 region, and extracellular field potentials were recorded using a glass microelectrode (3-12 M $\Omega$; filled with ACSF) also in the stratum radiatum. Stimulus intensity was adjusted to produce a response of $\sim 1 \mathrm{mV}$ amplitude. Test responses were elicited at $0.02 \mathrm{~Hz}$. Homosynaptic LTD was induced by prolonged low-frequency stimulation ( $1 \mathrm{~Hz}$ for $15 \mathrm{~min})$ (Dudek and Bear, 1992). Data are presented as the mean \pm SEM. One-way ANOVA (with Duncan's multiple range test for post hoc comparison) and Student's $t$ test were used for statistical analysis; $p<0.05$ was considered significant.

\section{Behavioral analyses}

\section{General experimental design}

Two sets of experiments (study 1 and study 2) were conducted in separate groups of adult female mice. In study 1, AC8 KO $(n=17)$ and WT controls $(n=14)$ that were 3-4 months of age when behavioral testing began were evaluated first for general locomotor activity during a $1 \mathrm{hr}$ period and then on the walking-initiation test from the sensorimotor battery (described below). Next, we quantified anxiety-related behaviors during repeated daily testing (over 3 consecutive days) in the elevated plus-maze. Two different types of plus-maze experiments were conducted. In one instance (study 1, experiment 1), plus-maze testing consisted of $5 \mathrm{~min}$ sessions conducted over 3 consecutive days with no other experimental manipulations included. The other plus-maze experiment (study 1, experiment 2), which was conducted 2 months after the first experiment, included restraining the same mice for $30 \mathrm{~min}$ immediately before testing them in the plus-maze on each of the 3 consecutive days. Separate groups of 3-month-old naïve AC8 KO $(n=11)$ and WT $(n=10)$ females were evaluated on the ledge, platform, and inclinedscreen tests from the sensorimotor battery.

In study 2, a second set of experiments was conducted using different groups of mice. In this second set of experiments, groups of naïve KO $(n=18)$ and WT $(n=13)$ mice were subjected to plus-maze testing in which each of the $3 \mathrm{~d}$ test sessions was preceded by $30 \mathrm{~min}$ of restraint. One month later the mice were retested on the plus-maze using the same procedures. Two weeks after completing the second plus-maze experiment, the mice were evaluated in terms of "open-field" behaviors exhibited in the enclosure used in study 1 during the $1 \mathrm{hr}$ locomotor activity test.

\section{One hour general locomotor activity}

Locomotor activity of the mice was evaluated over a $1 \mathrm{hr}$ period as described previously (Brosnan-Watters et al., 1996). Testing was performed in two transparent $(47.6 \times 25.4 \times 20.6 \mathrm{~cm}$ high $)$ polystyrene cages that contained a thin layer of wood chip bedding. Each cage was surrounded by a frame containing three pairs of photoelectric cells placed across the width of the cages, dividing the cages into four equal quadrants along their length. Each pair of photocells was connected to silent digital counters that recorded the number of infrared beam breaks. Activity counts (beam breaks) were summed across the three pairs of photocells at the end of the $1 \mathrm{hr}$ interval. Testing took place between 07:30 and 15:00 hr in a quiet room continuously illuminated by fluorescent lights. 


\section{One hour evaluation of open-field behaviors in previously stressed mice}

To assess exploratory behavior in mice that had been exposed previously to stressors, we evaluated the open-field behaviors and locomotor activity of the mice in study 2 during a $1 \mathrm{hr}$ test. Testing was performed in the same cages described above, although the data collection and variables analyzed were different. A frame containing four pairs of photocells along the shorter axis and eight pairs of photocells along the longer axis surrounded the cages, and the output of these photocell pairs was fed to an on-line computer (Hamilton-Kinder, LLC, Poway, CA). The system software (Hamilton-Kinder, LLC) was used to define a $33 \times 11 \mathrm{~cm}$ central zone and a peripheral or surrounding zone that was $5.5 \mathrm{~cm}$ wide with the sides of the cage being the outermost boundary. This peripheral area extended along the entire perimeter of the cage. Variables that were analyzed included the total number of ambulations, as well as the number of entries, the time spent and the distance traveled in the center area, and the time spent and the distance traveled in the area surrounding the center.

\section{Sensorimotor battery}

The general sensorimotor capabilities of the mice from study 1 were evaluated using the four tests described below that have been found previously to be sensitive for detecting acute drug-induced sensorimotor disturbances in mice (Brosnan-Watters et al., 1996, 1999), and a subset of the tests has been used to determine the onset of chronic disturbances in certain transgenic mice (Chiesa et al., 1998). Mice were evaluated over two test sessions for each of the four tests. The first session commenced at 09:00 hr, and the second session commenced $3 \mathrm{hr}$ later.

Inclined screen. Each mouse was placed on an elevated $(47 \mathrm{~cm}$ above the floor) wire mesh grid (16 squares per $10 \mathrm{~cm}$ ) that was inclined to $60^{\circ}$. The wire mesh grid was stretched across a wooden frame that was $15 \times$ $52 \mathrm{~cm}$, and tape was placed along the perimeter to prevent the mice from climbing around to the back of the apparatus. Each mouse was placed in the middle of the screen with its head oriented downward and timed for either how long it remained on the screen or how long it took to turn $180^{\circ}$ and climb to the top of the apparatus and rest its forepaws on top. A maximum score of $60 \mathrm{sec}$ was given if an animal did not fall.

Platform. Each mouse was timed for how long it remained on an elevated (47 cm above the floor) circular platform $(1.0 \mathrm{~cm}$ thick; $3.0 \mathrm{~cm}$ in diameter). A maximum score of $60 \mathrm{sec}$ was assigned if the mouse remained on the platform for the maximum amount of time or if it could climb down on a very thin pole that supported the platform without falling.

Ledge. Each mouse was timed for how long it could maintain its balance on a narrow $(0.75 \mathrm{~cm}$ thick) Plexiglas ledge without falling (60 sec maximum). A score of $60 \mathrm{sec}$ was also assigned if the mouse traversed the entire length $(51 \mathrm{~cm})$ of the Plexiglas ledge and returned to the starting place in $<60 \mathrm{sec}$ without falling.

Walking initiation. Each mouse was placed in the middle of a square outlined by white cloth tape $(21 \times 21 \mathrm{~cm})$ on a smooth black surface of a large table top. The time it took each mouse to leave the square (place all four paws outside of the tape) was recorded. The maximum time allowed was $60 \mathrm{sec}$.

\section{Elevated plus-maze}

Our apparatus is a modified version of that described by Lister (1987) consisting of two opposing open arms [ $35 \times 6.1$ (outer width) $\times 0.3 \mathrm{~cm}]$ and two opposing enclosed arms $(35 \times 6.1 \times 15 \mathrm{~cm})$ that extend from a central platform $(5.5 \times 5.5 \mathrm{~cm})$. The floor and walls of the maze were constructed of black Plexiglas. The maze is equipped with pairs of photocells configured in a 16 ( $x$-axis) by 16 ( $y$-axis) matrix, the output of which is recorded by a computer and interface assembly (HamiltonKinder, LLC). A software program (Hamilton-Kinder, LLC) enables the beam break data to be recorded and analyzed to quantify time spent, distance traveled, time spent at rest, and the numbers of entries made into the open and closed arms and the center area. These data were used to calculate the total arm entries, the percent of open arm entries [e.g., (open arm entries/total arm entries) $\times 100$ ], the percent of closed arm entries, the percent of open arm time (e.g., [open arm time (sec)/300 sec] $\times 100$ ), and the percent of closed arm time. The numbers of fine movements and $x$ - and $y$-axes ambulations were also recorded throughout the maze. The numbers of $x$ - and $y$-axes ambulations predominantly reflect locomotor activity in the closed and open arms, respectively, although a small percentage of $x$-axis ambulations are measured in the open arms and the same is true for $y$-axis ambulations in the closed arms. In study 2, various behaviors were also quantified from a videotaped record of the test sessions. The behaviors analyzed were stretch attend postures (SAPs) in the open and closed arms, open and closed arm head dips, and the time taken to leave the center area to first enter an arm. The SAPs were defined as exploratory postures in which the mouse stretches forward and retracts to its original position without walking forward. Head dips were characterized by exploratory movements of the head and shoulders over the sides of the maze. In the closed arms, head dips occur around the exiting corners of the arms nearest to the central area. Mice were tested from 08:00 to 16:00 hr in a darkened room where the only illumination came from a single incandescent $(60 \mathrm{~W})$ bulb. Test sessions commenced by placing a mouse in an opaque plastic tube and then removing the tube, allowing the mouse to explore the maze. Each test session lasted $5 \mathrm{~min}$, and mice were tested over 3 consecutive days. Mice to be restrained were transported to a room separate from the housing room and the behavioral-testing room. Each mouse was placed in a ventilated $50 \mathrm{ml}$ plastic tube. Mice were restrained for $30 \mathrm{~min}$ and then taken into the testing room and evaluated on the plus-maze. The mice were restrained before plus-maze testing on each of the $3 \mathrm{~d}$ test sessions for each of the three experiments that involved restraint.

\section{Olfactory testing}

AC8 KO and WT male mice at $8-12$ weeks of age $(n=4-5$ per odorant concentration) were tested for the ability to detect odorants and associate them with an aversive stimulus as described previously (Griff and Reed, 1995). Briefly, after fluid restriction of $1 \mathrm{hr}$ of access to fluid daily for 1 week, mice were provided solutions containing $10^{-3}-10^{-8} \mathrm{M}$ isovaleric acid or $10^{-3}-10^{-4}$ dilutions of the pentadecalactone stock solution for $10 \mathrm{~min}$ followed by intraperitoneal injection of $0.6 \mathrm{M}$ lithium chloride. Twenty-four hours later, two water bottles were placed in the cages, one with odorant and one without. After $24 \mathrm{hr}$, the volume ingested from each bottle was determined, and the positions of the bottles were reversed. Volume was again measured after an additional $24 \mathrm{hr}$, and the preference ratio (volume of odorant solution ingested/total volume ingested) was determined for the $48 \mathrm{hr}$ period. To ensure that an underlying preference or aversion to the odorant-containing solution was not present, we tested WT or KO mice $(n=4-5)$ without the aversive stimulus.

\section{Statistical analyses for the behavioral tests}

The data from the behavioral tests were analyzed using ANOVA models. Except for the sensorimotor and plus-maze data, one-way ANOVAs were conducted for a given variable or test, e.g., the number of entries into the central zone of the open field or locomotor activity counts. Two-way ANOVAs containing one between-subjects variable, group (AC8 KO vs WT), and one within-subjects (repeated measures) variable, test sessions (one to two), were used to analyze the data from the sensorimotor tests. Similar ANOVAs on repeated measures were used to analyze each dependent variable generated in the plus-maze experiments except that the within-subjects (repeated measures) variable was test days (one to three). Simple main effects of group were calculated for each test day after a significant main effect of group or a significant group-by-test day interaction. $\alpha$ levels were adjusted for the withinsubjects variables test days and the group-by-test days interaction using the Greenhouse-Geisser correction to control for violations of sphericity/compound symmetry.

\section{Neuroendocrine response to restraint}

Three-month-old AC8 KO and WT males ( $n=3-4$ per group) that had been singly housed were subjected to retroorbital phlebotomy $2-3 \mathrm{hr}$ after lights-on either (1) in the basal state without previous manipulation, (2) in the basal state but after $1 \mathrm{hr}$ of restraint stress daily for 1 week, (3) immediately after an initial $1 \mathrm{hr}$ of restraint, or (4) after $1 \mathrm{hr}$ of restraint preceded by $1 \mathrm{hr}$ of daily restraint for 1 week. Serum corticosterone was determined by RIA as described previously (Muglia et al., 1995). Data are presented as the mean \pm SEM, with statistical significance determined by ANOVA.

\section{Immunohistochemistry}

Nonstressed AC8 KO and WT mice and KO and WT mice that had been subjected to $1 \mathrm{hr}$ of restraint stress and then returned to their home cages for $2 \mathrm{hr}(n=3$ males at 2-3 months of age per genotype and treatment group) were deeply anesthetized with $1 \mathrm{ml}$ of $2.5 \%$ Avertin and transcardially perfused with Dulbecco's PBS (D-PBS) followed by $4 \%$ para- 
Figure 1. Targeted inactivation of AC8. A, Strategy for AC8 gene disruption. Homologous recombination between the targeting vector and the WT AC8 locus results in the deletion of exon 1 and $2 \mathrm{~kb}$ of the $5^{\prime}$-flanking region in the targeted AC8 locus. The open box in exon 1 represents 5 -untranslated leader sequence, and the stippled area shows the region coding for the first 320 amino acids. Genes and restriction sites indicated are as follows: $B, \operatorname{Bam} \mathrm{HI} ; E$, EcoRI; H, HindIII; pgk-neo, phosphoglycerate kinase promoter-neomycin resistance gene; $p g k-t k$, phosphoglycerate kinase promoter-herpes simplex virus thymidine kinase gene; $S, S a c \mathrm{I} ; X b, X b a \mathrm{I}$; and $X h$, $X$ hoI. $B$, Absent AC8 mRNA in AC8 KO mice. Reverse-transcription PCR of total hypothalamic RNA used gene-specific primers from the region deleted after homologous recombination with the targeting vector $\left(5^{\prime} A C 8\right)$ and a region of the AC8 gene remaining after targeting ( $\left.3^{\prime} A C 8\right)$. Shown is an ethidium bromide-stained agarose gel demonstrating the expected products for each primer pair in WT $(+/+)$ and heterozygous $(+/-)$ mice but not in the $\mathrm{KO}(-/-)$ mice. The vasopressin $(V P)$ mRNA amplification product is detected in all samples, verifying hypothalamic RNA integrity.

formaldehyde in D-PBS. Brains were post-fixed by immersion in $4 \%$ paraformaldehyde for $24 \mathrm{hr}$ at $4^{\circ} \mathrm{C}$ and cryoprotected in $10 \%$ sucrose in D-PBS. Immunohistochemical analysis was performed on free-floating sections cut at $3558 \mathrm{~m}$ on a cryostat. After blocking in 3\% normal goat serum in PBS for 30 min, sections were incubated with a 1:1000 dilution of a polyclonal rabbit anti-phosphoCRE-binding protein (antiphosphoCREB) antibody (New England Biolabs, Beverly, MA) in D-PBS with $1 \%$ goat serum. Peroxidase staining was visualized with a Vectastain Elite ABC kit (Vector Laboratories, Burlingame, CA). Staining intensity was quantitated using NIH Image software and analyzed for statistical significance between genotypes by ANOVA.

\section{RESULTS}

\section{Production of AC8 KO mice}

To generate AC8 KO mice, we constructed a targeting vector that replaces $2 \mathrm{~kb}$ of the AC8 5'-flanking region and all of exon 1 (encoding the translation initiation site and the first 320 amino acids of the AC8 protein) with a phosphoglycerate kinaseneomycin resistance cassette (Fig. $1 A$ ). One of 150 G418- and gancyclovir-resistant ES clones underwent homologous recombination as determined by Southern blot analysis using a hybridization probe external to the region of homology contained within the targeting vector. We generated several male chimeras from this ES clone that transmitted the mutant allele through the germline.

Matings of mice heterozygous for the disrupted AC8 allele resulted in the generation of homozygous AC8-deficient mice in numbers not reduced from the expected Mendelian frequency, with the homozygotes representing $17 / 79$ (34\%) of the initial progeny. To ensure that deletion of the promoter region and exon 1 had not allowed production of a truncated AC8 protein, we performed RT-PCR analysis of hypothalamic RNA using amplification primers both from the region of the AC8 gene that had been deleted and from a $3^{\prime}$ region of the mRNA that had not been deleted. No products from either primer pair were detected in AC8 KO hypothalamus (Fig. 1B) or hippocampus (data not shown).

\section{Pattern of calcium-stimulated AC activity in AC8 KO mice}

To assess which regions of the brain would most likely manifest altered function as a consequence of loss of AC8, we compared the patterns of expression of AC8 and AC1, an abundant AC isoform in the brain significantly stimulated by calcium and/or calmodulin (Xia et al., 1991; Cooper et al., 1995), by in situ hybridization in WT and AC8 KO mice. In general, despite expression of both $\mathrm{AC}$ isoforms in many brain regions, the cell populations within these regions expressing each $\mathrm{AC}$ isoform differed. Comparison of AC1 expression in WT and AC8 KO mice revealed no qualitative alteration in the sites of AC1 mRNA expression as a consequence of loss of AC8 activity (Fig. 2). As we have reported previously (Muglia et al., 1999), AC8 mRNA is most abundantly expressed within the olfactory bulb, thalamus, habenula, CA1 region of the hippocampus, and hypothalamus in WT mice (Fig. 2).

To assess alterations in calcium-stimulated AC activity in the AC8 KO mice directly, we measured brain region-specific cAMP generation as a function of calcium concentration (Fig. 3). Consistent with the in situ hybridization findings, calcium-stimulated adenylyl cyclase activity was almost entirely absent from the regions in which AC8 predominated such as the hypothalamus, olfactory bulb, thalamus, and brainstem. Calcium-stimulated AC activity was reduced $\sim 40-50 \%$ in the hippocampus, in accord with the loss of AC8 activity within the CA1 region together with persistent hippocampal AC1 activity (Fig. 2). Basal AC activity, as determined in the absence of calcium, is not altered in the AC8 KO mice (Fig. 3).

\section{Phenotype of AC8 KO mice}

AC8 KO mice derived from heterozygous matings appeared grossly indistinguishable from their WT and heterozygous littermates and were fertile. Analysis of growth of the $\mathrm{KO}$ mice revealed a tendency for both male and female AC8 KO mice to be somewhat smaller than the corresponding WT controls (Fig. $4 A, B)$. The AC8 $\mathrm{KO}$ female mice gained weight in a manner similar to that of WT females until day of life 30, at which point they began to diverge significantly $(p<0.05)$. The AC8 KO females then remained 10-15\% smaller than WT females $(p<$ $0.0001)$. In contrast, $\mathrm{KO}$ male mice grew in a manner identical to that of WT mice until day of life 45 and then transiently grew more slowly between day of life 45 and $92(p<0.01)$, after which point differences in WT and KO males were not significant. The observed differences in weight gain were not caused by differences in appetite, because the absolute amount of food ingested daily did not differ between the genotypes, and food intake normalized 

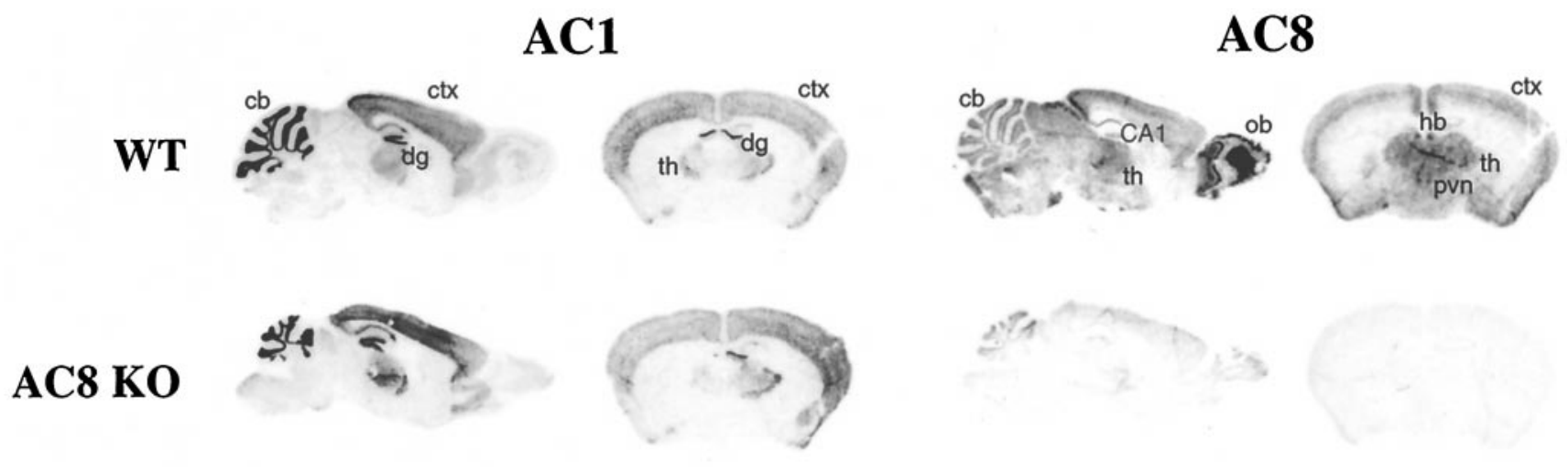

Figure 2. Localization of AC1 and AC8 mRNA in WT and AC8 KO brain. Representative in situ hybridization autoradiograms of WT (top row) and AC8 KO (bottom row) mice are shown. Adjacent sagittal and coronal sections were hybridized to probes specific for AC1 (left) or AC8 (right). AC1 mRNA hybridization is strongest in the cerebellum $(c b)$, cerebral cortex $(c t x)$, and dentate gyrus $(d g)$ of the hippocampus. AC8 mRNA is detected in the olfactory bulb $(o b)$, thalamus $(t h)$, cortex, habenula $(h b)$, CA1 region of the hippocampus, and paraventricular nucleus of the hypothalamus ( $p v n$ ), as well as other brain regions in WT, but not AC8 KO, mice.

to body weight was greater in the KO mice as compared with WT (data not shown).

Because of the high level of expression of AC8 mRNA in the olfactory bulb, we sought to determine whether olfactory learning or odorant sensing had been impaired in the AC8 KO mice. We used a conditioned avoidance assay (Griff and Reed, 1995) to determine whether the $\mathrm{KO}$ mice could smell a given odorant and associate it with an aversive stimulus. The preference ratio, defined as the volume of odorant solution ingested per total amount of solution ingested as measured in a two-bottle system, has been shown to reflect olfaction accurately. Both WT and AC8 KO mice avoided the odorant (isovaleric acid or pentadecalactone)containing solutions when the odorants had been paired with the aversive stimulus and showed similar thresholds for the ability to detect the odorants in the drinking water (Fig. 4C,D).

\section{Impaired long-term depression in AC8 KO mice}

Although the loss of both $\mathrm{AC} 1$ and $\mathrm{AC} 8$ activity results in defects in late-phase long-term potentiation (L-LTP) and long-term memory (LTM), a single deficiency of each isoform causes impairment of neither L-LTP nor LTM (Wong et al., 1999). Because behavioral stress-induced learning and alteration in synaptic strength have been associated with the induction of LTD in the CA1 region of the hippocampus (Kim et al., 1996; Xu et al., 1997; Manahan-Vaughan and Braunewell, 1999), we proceeded to evaluate the ability of hippocampal slices from AC8 KO mice to demonstrate LTD after low-frequency (1 Hz; $15 \mathrm{~min})$ CA1 stimulation. In contrast to WT mice, which demonstrated a significant reduction in field EPSP after low-frequency stimulation, AC8 KO mice did not elicit LTD (Fig. 5).

\section{Stress-related behavioral and neuroendocrine effects in AC8 KO mice}

Previous behavioral evaluation of AC8 KO mice demonstrated normal passive avoidance, contextual, and cued-learning responses (Wong et al., 1999). Before analyzing the specific effects of stress on the induction of anxiety in AC8 KO mice, they and WT mice were first evaluated on a $1 \mathrm{hr}$ test of general locomotor activity and a battery of sensorimotor measures. These tests were done to ensure that there were no inherent abnormalities in AC8 KO mice that might confound the interpretation of behavioral performance on subsequent tests of anxiety.
A. thalamus

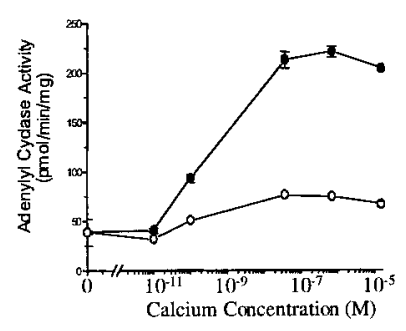

B. hypothalamus

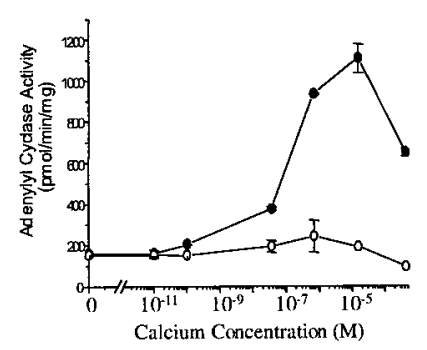

C. olfactory bulb

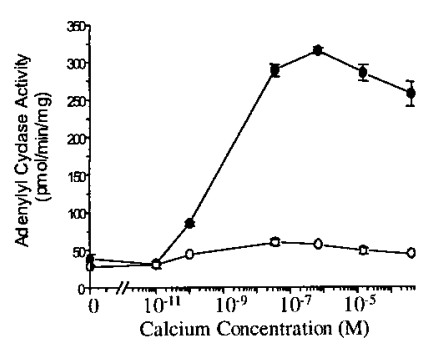

Figure 3. Brain-region specific AC activity in WT and AC8 KO mice. Calcium-stimulated AC activity determinations from freshly excised thalamus $(A)$, hypothalamus $(B)$, olfactory bulb $(C)$, hippocampus $(D)$, and brainstem $(E)$ from WT (closed circles; $n=5$ ) or AC8 KO (open circles; $n=5$ ) mice are displayed. Nearly all AC8 KO brain regions, with the exception of the hippocampus, demonstrated profound deficiency in the ability to generate cAMP in response to $\mathrm{Ca}^{2+}$. 
A

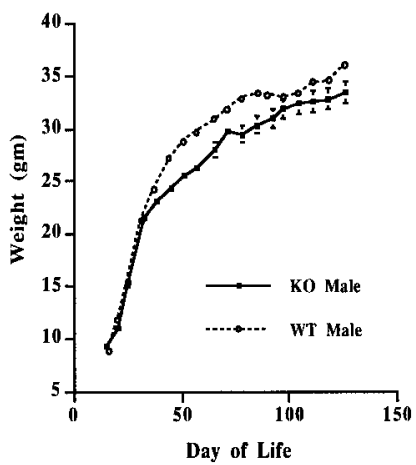

C

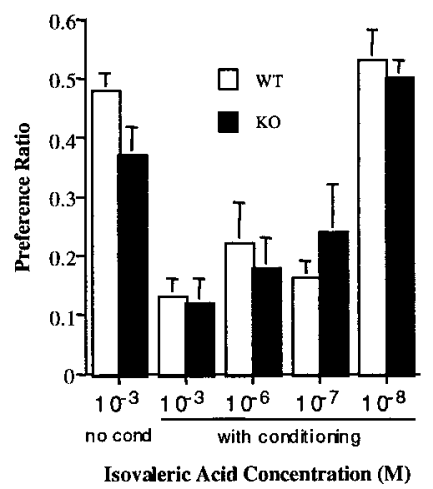

B

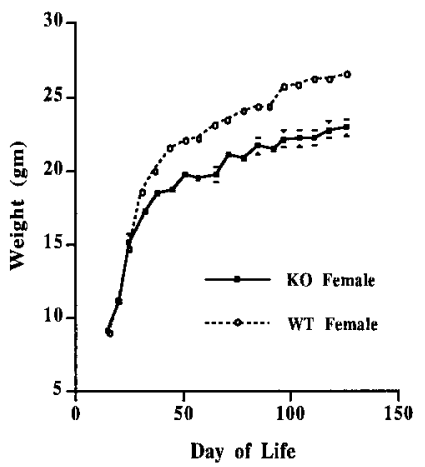

D

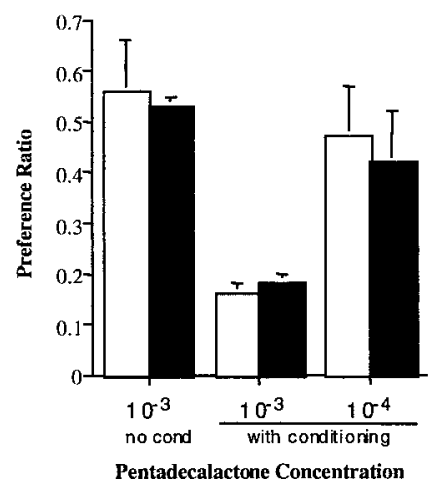

Figure 4. Growth and olfaction in AC8 KO mice. $A$, Growth curves of WT $(n=23)$ and AC8 KO $(n=27)$ male mice. Differences in weights between males of each genotype achieved statistical significance between day of life 45 and $92(p<0.01)$. $B$, Growth curves of WT $(n=26)$ and AC8 KO $(n=17)$ female mice. Differences in weights between females of each genotype achieved statistical significance at day of life $30(p<0.05)$. AC8 KO females remained smaller than WT females as adults $(p<$ 0.0001). $C, D$, Preference testing for isovaleric acid $(C)$ and pentadecalactone $(D)$. Adult male mice $(n=4-5$ per odorant concentration and genotype) were tested with and without (no cond) the conditioning aversive stimulus. The preference ratio represents the total amount of odorant-containing solution ingested per total amount of liquid ingested.

\section{Behavioral effects}

No differences were found between the AC8 KO and WT mice in general locomotor activity (see Fig. 9A). The two groups also performed similarly on the ledge, platform, and inclined-screen tests within the sensorimotor battery (Fig. 6A-C) demonstrating that they did not differ in balance, strength, and coordination. However, group performances significantly differed on the walking-initiation portion of the battery (Fig. 6D). The AC8 KO mice took less time to leave a defined perimeter outlined on a large tabletop over two test sessions compared with WT mice $\left[F_{(1,29)}=6.71 ; p=0.015\right]$, with the greatest difference between groups occurring during the first test session $(p=0.008)$. Previous drug studies in rats and mice (Wozniak et al., 1990; BrosnanWatters et al., 1996) suggest that these differences in the latency to initiate movement in an open area reflect altered emotionality (e.g., anxiety) rather than differing motoric capacity.

To evaluate differences in anxiety further, we tested both groups of mice on the elevated plus-maze. Spontaneous behaviors exhibited in the maze reflect an innate aversion that rodents have to elevated, open spaces. Anxiety is inferred from the analysis of dependent variables that reflect an avoidance of the open arms. We conducted two groups of studies to investigate the effects of

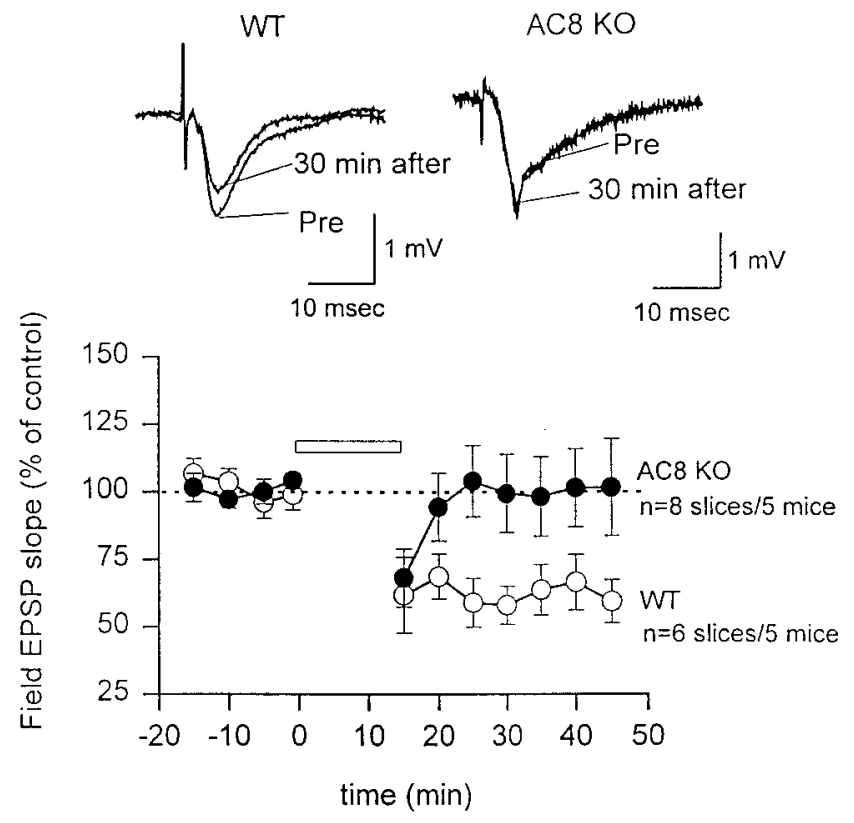

Figure 5. Impaired long-term depression in AC8 KO mice. Lowfrequency stimulation ( $1 \mathrm{~Hz} ; 15 \mathrm{~min}$; open horizontal bar $)$ induced LTD in the CA1 region of the hippocampus from WT mice (open circles; $61.8 \pm$ $9.2 \% ; n=6$ slices from 5 mice; $p<0.05$ comparing the potential $25-30$ min after stimulation with the average of the potential before stimulation). However, LTD was blocked in mice lacking AC8 (closed circles; $101.4 \pm 14.4 \% ; n=8$ slices from 5 mice; $p<0.05$ vs WT after stimulation). Inset, Representative recordings of the EPSP before and 30 min after low-frequency stimulation in WT (left) and AC8 KO (right) mice are shown.

two independent variables known to alter plus-maze performance: repeated test exposure (Espejo, 1997) and restraint stress immediately preceding plus-maze testing (Gorman and Dunn, 1993).

In the first experiment (study 1, experiment 1), we tested mice over 3 successive days without restraint before any test. ANOVAs conducted on the plus-maze variables indicated that there were no significant overall main effects of group for any variable (Fig. 7). However, because a single previous undrugged exposure to plus-maze testing reduces or abolishes the subsequent efficacy of anxiolytics (Rodgers et al., 1992; Rodgers and Shepherd, 1993), we postulated that daily exposure to testing may have altered innate differences in anxiety-related behaviors between groups on specific days. We therefore proceeded to conduct pairwise comparisons for each dependent variable as a function of test day. On the first test day, significant differences between the naïve AC8 KO and WT mice were found only for $y$-axis ambulations, which reflect open arm locomotor activity $\left[F_{(1,28)}=6.12 ; p=\right.$ 0.02; Fig. $7 D$ ]. However, on the second test day differences emerged on three variables related to open arm behaviors. The $\mathrm{KO}$ mice spent a significantly greater percentage of time $\left[F_{(1,28)}\right.$ $=6.16 ; p=0.019 ;$ Fig. $7 A]$ and traveled a significantly greater distance $\left[F_{(1,28)}=4.57 ; p=0.041\right.$; Fig. $\left.7 B\right]$ in the open arms than did the WT mice, and the percent of open arm entries was significantly greater for the KO compared with the WT mice (data not shown). The trends for the variables continued, although they did not achieve statistical significance, when repeated on day 3 (Fig. $7 A, B$ ). The significant pairwise comparisons found on specific test days in study 1, experiment 1, suggested that AC8 $\mathrm{KO}$ mice displayed less anxiety than did WT mice in the plus- 
A
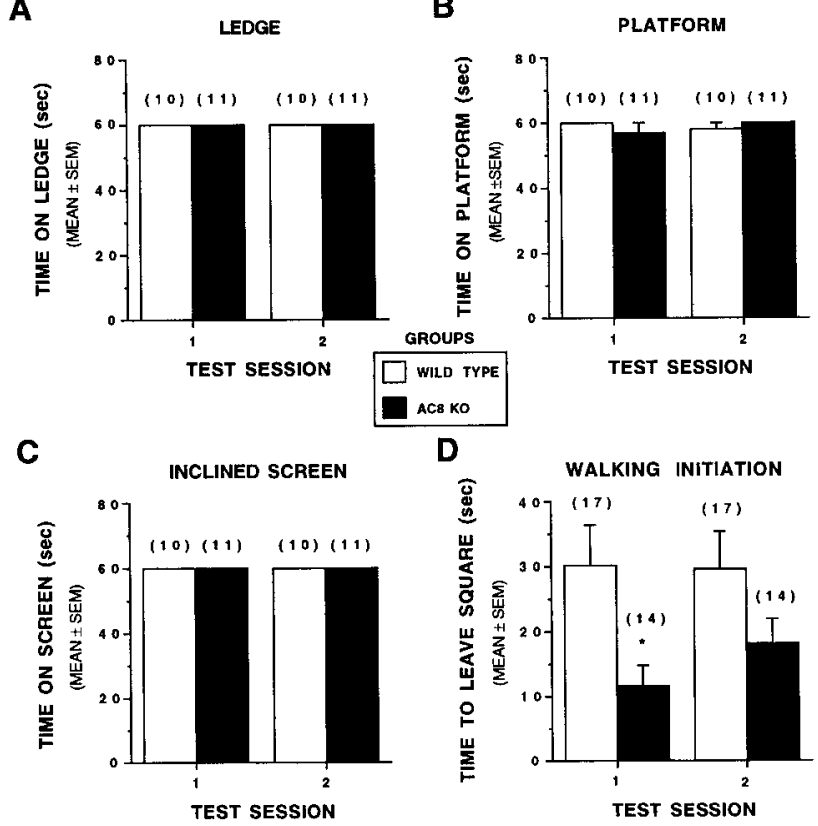

Figure 6. Sensorimotor analyses of AC8 $\mathrm{KO}$ and WT mice. Both groups performed well on the ledge $(A)$, platform $(B)$, and inclined-screen $(C)$ tests, with no differences found between genotypes. On the walkinginitiation test $(D), \mathrm{AC} 8 \mathrm{KO}$ mice took significantly less time to leave a defined perimeter over the two test sessions $\left[F_{(1,29)}=6.71 ; p=0.015\right]$. The number of mice per group is indicated in parentheses above the corresponding bar. ${ }^{*}, p=0.008$.

maze, particularly in the degree to which anxiety increased across test days.

We next subjected the same AC8 KO and WT mice to $30 \mathrm{~min}$ of restraint stress before testing them on the plus-maze to potentiate innate differences in anxiety between the two groups. Restraining the mice before testing them on the plus-maze (study 1 , experiment 2) resulted in significant main effects of group for several dependent variables. The AC8 KO mice spent a significantly greater amount of time, and traveled a significantly greater distance, in the open arms than did the WT mice $\left[F_{(1,28)}=5.68\right.$ $(p=0.024)$ and $F_{(1,28)}=5.79(p=0.023)$, respectively; Fig. $7 A, B]$. Evaluation of the numbers of ambulations along the $x$ - and $y$-axes also yielded significant main effects of group, with the KO mice exhibiting greater levels of activity in both the open and closed arms $\left[F_{(1,28)}=8.40(p=0.007)\right.$ and $F_{(1,28)}=4.67(p=$ 0.039 ), respectively; Fig. $7 C, D]$. Thus, the restraint stress and/or second exposure to repeated daily testing in the plus-maze increased differences in anxiety-related behaviors, with the $\mathrm{KO}$ mice consistently exhibiting less evidence of anxiety.

To confirm the findings in study 1 , experiment 2 , we subjected additional groups of naïve AC8 KO and WT mice to the same $3 \mathrm{~d}$ restraint stress and plus-maze protocol (study 2, experiment 1 ). These results were similar to those observed in study 1 , experiment 2, again indicating that the repeated restraint and testing resulted in more anxiety in WT than in AC8 $\mathrm{KO}$ mice (Fig. 7). For example, significant main effects of group were found for ambulations along the $x$ - and $y$-axes indicating that the AC8 KO mice were more active within both arms compared with the WT mice when restraint preceded plus-maze testing $\left[F_{(1,29)}=8.97\right.$ $(p=0.006)$ and $F_{(1,29)}=4.24(p=0.049)$, respectively; Fig. $7 C, D]$. In the second experiment conducted in study 2 , we retested mice on the same restraint and plus-maze protocol used in experiment 1 after an intervening period of 1 month, during which time no behavioral testing was conducted. This second exposure revealed even larger differences in open arm behaviors between the groups (Fig. 7).

Ethologically based indices of anxiety (Rodgers and Cole, 1993; Espejo, 1997) such as head dips and SAPs were also analyzed in the plus-maze. In study 2, experiment 1 , WT mice emitted more closed arm SAPs $(p<0.0005$; Fig. $8 A)$ and head dips ( $p=0.001$; Fig. $8 C)$ than did AC8 KO mice on the first test day, suggesting greater risk assessment by the WT mice. In agreement with greater risk assessment, the WT mice also consistently took longer to leave the center area to first enter an arm of the plus-maze ( $p=0.023$; Fig. $8 B)$. In contrast, the AC8 KO mice emitted more head dips over the side of the open arms (a behavior anticipated to induce anxiety) than did the WT mice in both studies, achieving a significant main effect of group during study 2 , experiment $2(p=0.036$; Fig. $8 D)$.

Two weeks after completion of the second restraint and plusmaze experiment in study 2 , we evaluated the same mice on several measures in the open field. In agreement with findings from the restraint and plus-maze testing, the AC8 KO mice exhibited a greater number of ambulations in the open field compared with the WT mice (Fig. 9A). In addition, the KO mice also made more entries into and traveled a greater distance within the central area relative to the WT mice (Fig. 9B,C).

\section{Neuroendocrine effects}

Because AC8 is the only calcium-stimulated AC expressed in the hypothalamus, we evaluated the response of the hypothalamicpituitary-adrenal axis to acute and chronic stress to determine whether glucocorticoid production had been impaired. We subjected AC8 KO and WT mice to either acute $(1 \mathrm{hr})$ or chronic restraint ( $1 \mathrm{hr}$ daily for $7 \mathrm{~d}$ ) stress followed by determination of plasma corticosterone concentration. In naïve KO and WT mice before their initial restraint, no difference in plasma corticosterone concentration was found (Fig. 10). After the initial $1 \mathrm{hr}$ of restraint, corticosterone levels increased equivalently in both genotypes. Adaptation to chronic restraint stress, however, differed between the two genotypes. Evaluation of serum corticosterone in WT mice immediately before their seventh day of $1 \mathrm{hr}$ restraint stress showed no difference from the basal corticosterone in naïve WT mice. The chronically restrained WT mice, however, exhibited a significantly augmented production of corticosterone after the seventh restraint compared with that of WT mice after the initial restraint (Fig. 10). In contrast, AC8 KO mice exhibited an elevated basal corticosterone level before their final restraint in comparison with naïve KO and WT mice. No significant augmentation of serum corticosterone after the final restraint in comparison with that after the first restraint occurred in the $\mathrm{KO}$ mice, but the corticosterone measured after the final restraint did not significantly differ from that achieved by WT mice (Fig. 10).

\section{Cellular basis of the altered stress response in AC8 KO mice}

AC8 is expressed in several brain regions associated with the stress response and is completely deficient in all of these areas in the AC8 KO mice. Reduced AC activity should result in diminished downstream signaling including protein kinase A-mediated CREB activation. To implicate specific brain regions in the alteration in stress-induced anxiety in the KO mice, we analyzed the pattern of expression of the active phosphorylated form of CREB (pCREB) in WT and KO mice (Fig. 11). Basal (unstressed) 
$\mathbf{A}$

$\%$ OF TIME SPENT IN OPEN ARMS
B DISTANCE TRAVELED IN OPEN ARMS
Figure 7. Restraint stress and repeated testing alters anxiety-related behaviors in the elevated plus-maze. Effects on four different variables are shown: the percent of time in the open arms $(A)$, the distance traveled in the open arms $(B)$, the number of $x$-axis (closed arm) ambulations $(C)$, and the number of $y$-axis (open arm) ambulations $(D)$. Mice were tested on 3 consecutive test days under each of the following conditions: study 1 , experiment 1 , mice naïve to the plusmaze on test day 1 and no restraint before testing; study 1 , experiment 2 , same mice used in study 1 , experiment 1 , except it is 2 months later with restraint for 30 min each day before testing; study 2 , experiment 1 , different naïve groups of mice restrained for $30 \mathrm{~min}$ each day before testing; study 2, experiment 2 , same mice used in study 2 , experiment 1 , retested with the same restraint protocol 1 month later. $\dagger$, Significant main effect of group; *, significant simple main effects of group; + , borderline nonsignificance of simple main effects. EXP., Experiment.

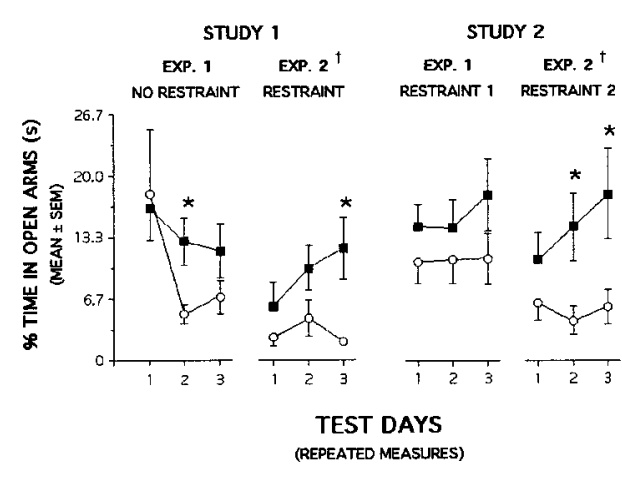

C

$X$-AXIS AMBULATIONS (CLOSED ARM ACTIVITY)

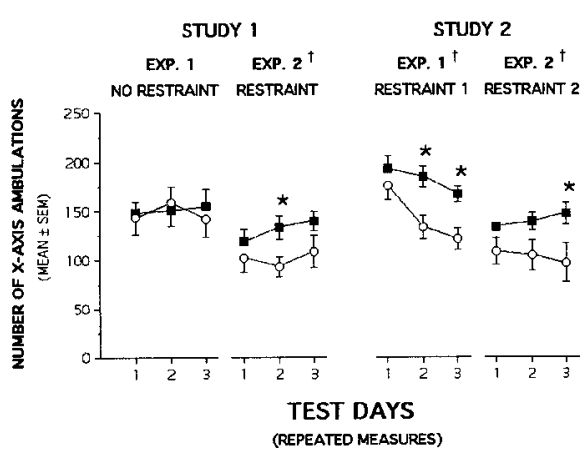

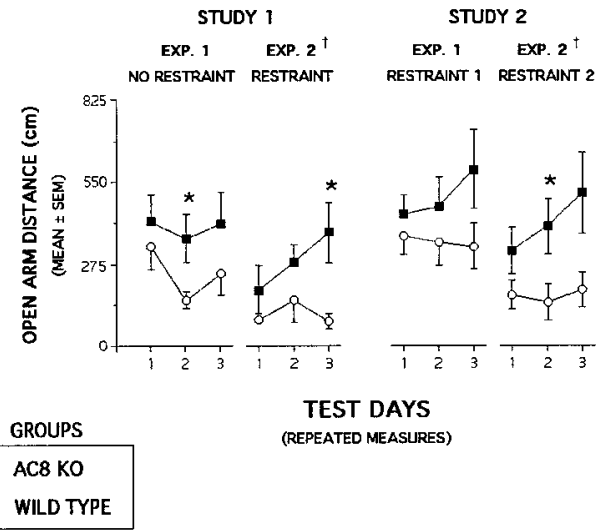

D
pCREB immunoreactivity revealed no significant differences between AC8 KO and WT mice in any brain region (Fig. 11B). To evaluate sustained pCREB induction, we analyzed KO and WT mice $2 \mathrm{hr}$ after restraint stress. We found pCREB immunoreactivity consistently and significantly decreased in the $\mathrm{KO}$ mice in the CA1 region of the hippocampus after restraint in comparison with WT mice (Fig. 11). No consistent differences in pCREB expression were observed in the dentate gyrus and cerebral cortex (Fig. 11) or other brain regions including the hypothalamus, pyriform cortex, amygdala, and thalamus (data not shown). Interestingly, analysis of pCREB expression immediately after $1 \mathrm{hr}$ of restraint revealed significant immunoreactivity in the dentate gyrus of both genotypes but no CA1 staining in either WT or KO mice ( $n=3$ per genotype; data not shown). Thus, CA1 CREB phosphorylation is a sustained, time-dependent process, which is disrupted in the AC8 $\mathrm{KO}$ mice.

\section{DISCUSSION}

To determine the role of the calcium-stimulated ACs in the behavioral and neuroendocrine response to stress, we report the generation and characterization of AC8-deficient mice. Our targeting strategy, which deleted the AC8 gene promoter region and exon 1, resulted in complete AC8 deficiency as demonstrated by the absence of AC8 mRNA and the loss of calcium-stimulated AC activity in brain regions where AC8 predominates. In situ hybridization studies in AC8 KO mice, together with the direct analysis of AC activity, further demonstrated that significant induction of
AC1 in cell populations primarily expressing AC8 in WT mice does not occur.

Surprisingly, despite normal hippocampal L-LTP and LTM (Wong et al., 1999), AC8 KO mice manifest significant impairment in hippocampal CA1 LTD. Calcium-stimulated AC activity is reduced, but not absent, in the hippocampi of AC8 $\mathrm{KO}$ mice, as would be expected on the basis of abundant AC1 expression in the dentate gyrus, lower AC1 expression in the CA1 region, and loss of AC8 in the CA1 region. Despite evidence of AC1 mRNA in the CA1 region, we find that loss of AC8 cannot be compensated for by the residual AC1 activity. The inability of AC1 to maintain LTD in AC8 KO mice could result from differences between the isoforms including sensitivity to calcium for activation (Villacres et al., 1995), subcellular localization, or subpopulations of expressing cells. These possibilities will be evaluated in our ongoing studies. Hippocampal CA1 LTD has been found previously to be dependent on NMDA receptor (Dudek and Bear, 1992; Kim et al., 1996; Zhuo et al., 1999) and protein kinase A RI $\beta$ and $C \beta_{1}$ subunit (Brandon et al., 1995; Qi et al., 1996) function. Our demonstration of a critical role for AC8 in CA1 LTD further elucidates the molecular basis of this response by defining the $\mathrm{AC}$ isoform linking the intracellular influx of calcium resulting from NMDA receptor activation to the generation of cAMP for activation of protein kinase A. The dependence of CA1 LTD on AC8 activity suggests region-specific differences in the mechanisms for LTD within the hippocampus. For example, 
$\mathbf{A}$

\section{CLOSED ARM SAPS}

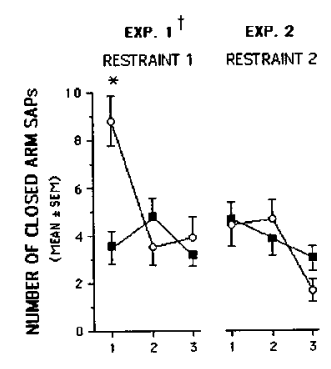

TEST DAYS (REPEATED MEASURES)

\section{C}
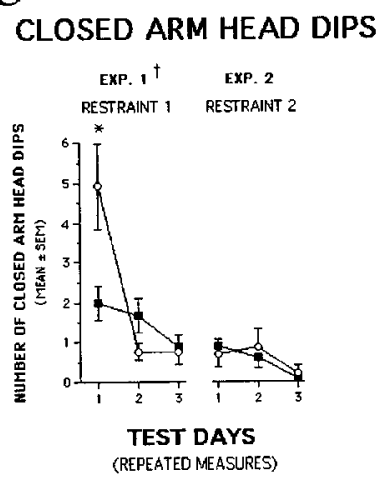

Figure 8. Effects of restraint stress and repeated plus-maze testing on ethological variables. $A, C$, When first exposed to the restraint/plus-maze protocol (study 2, test day 1, experiment 1$)$, the WT mice $(n=13)$ exhibited significantly $(*)$ greater numbers of closed arm SAPs $(A)$ and closed arm head dips $(C)$ compared with that of the AC8 KO mice $(n=$ 18 ). These effects were large enough to produce significant main effects of group $(\dagger)$ for both variables in experiment $1 . B$, The WT mice compared with the AC8 KO mice took consistently longer to exit the center area with a significant main effect of group $(\dagger)$ found in study 2 , experiment 1. Substantial differences $(+)$ exhibited on test day $1(p=0.051)$ contributed greatly to this effect. $D$, In contrast, the AC8 KO mice consistently exhibited more head dips in the open arms. A significant main effect of group $(\dagger)$ was found for study 2 , experiment 2 , and analysis of the simple main effects of group indicated that the KO mice compared with the WT mice exhibited significantly $(*)$ more open arm head dips on test day 2 (experiment 2).

mossy fiber synapses on CA3 pyramidal cells require metabotropic glutamate receptor-mediated decreases in adenylyl cyclase and protein kinase A activity for the induction of LTD (Tzounopoulos et al., 1998), whereas LTD in the medial perforant path of the dentate gyrus is contributed to by activation of both protein kinase A and C (Huang et al., 1999).

Enhancement of LTD occurs after behavioral stress in normal rodents (Kim et al., 1996; Xu et al., 1997; Manahan-Vaughan and Braunewell, 1999) and has been proposed as an important component of stress-induced learning. The behaviors exhibited by AC8 $\mathrm{KO}$ mice in the elevated plus-maze together with their impaired LTD are in accord with this hypothesis. Indeed, although naïve AC8 KO mice did not differ from WT mice in the exploration of the open arms of the elevated plus-maze, when repetitively tested or subjected to a defined stressor such as restraint or previous exposure to the plus-maze, clear genotypic differences emerged. WT mice exhibited evidence of heightened anxiety after previous testing or restraint in the elevated plus- maze, whereas the $\mathrm{KO}$ mice had little change in their responses. Videotape analysis of ethological variables showed further differences between AC8 $\mathrm{KO}$ and WT mice. The greater number of SAPs and closed arm head dips exhibited by WT mice suggest that the WT mice engage more frequently in risk assessment behaviors related to their defense repertoires when first exposed to the relatively protected closed arms of the plus-maze. The number of times these behaviors were exhibited dropped precipitously in the WT mice on subsequent exposures to the plus-maze or with restraint, which may have been caused by fear sensitization from the repeated testing and/or additional stressor (Rodgers et al., 1997). On the other hand, the AC8 KO mice demonstrated a greater number of open arm head dips, a behavior that would be expected to produce substantial anxiety in WT mice (Rodgers and Shepherd, 1993; Espejo, 1997).

Consistent with the findings in the elevated plus-maze, AC8 $\mathrm{KO}$ mice exhibited increased locomotor activity in the open field after previous exposure to the restraint and plus-maze protocol but indistinguishable general locomotor activity in comparison with WT mice when both genotypes were naïve. Thus, the differences in anxiety observed between the AC8 KO and WT mice in the plus-maze were not specific to only this testing technique as demonstrated by the open-field results, which closely paralleled the plus-maze findings. Furthermore, in accord with the heightened anxiety observed in WT mice, WT mice significantly augmented peak adrenal glucocorticoid synthesis after repeated restraint stress. Although AC8 KO mice did not augment peak plasma glucocorticoid levels immediately after the final restraint, suggesting less sensitization as a result of the previous stress, we cannot exclude an alteration in the temporal pattern of the $\mathrm{KO}$ corticosterone response. Differences in the timing of the corticosterone response between genotypes may be reflected by the elevated basal corticosterone level found in the AC8 KO mice preceding the final restraint. Alternatively, the elevated basal corticosterone level in the AC8 $\mathrm{KO}$ mice, a finding also reported after surgical lesions of the hippocampus (Jacobson and Sapolsky, 1991), may be another manifestation of impaired hippocampal function along with attenuated LTD and CREB phosphorylation.

The mechanism by which AC8 deficiency results in impaired stress-induced anxiety may be quite complex, because AC8 is expressed in several regions associated with the stress response. Although impaired LTD implicates the CA1 region of the hippocampus as a potential contributor to the alteration in their behavioral stress response, the altered response to chronic stress we describe in the AC8 KO mice could have resulted from the abnormal integration of stimuli in more than one brain region. To assess biochemical changes in specific regions throughout the CNS associated with the response to restraint stress, we analyzed pCREB immunoreactivity. Despite substantial reductions in calcium-stimulated AC activity in many brain regions in AC8 $\mathrm{KO}$ mice, no consistent differences in pCREB between WT and KO mice were found outside the CA1 region after stress. Although this finding does not exclude a role for AC8 in modulating stress-induced neuronal function in sites such as the thalamus, amygdala, and hypothalamus, intact CREB activation in these other sites indicates that other ACs or AC-independent mechanisms of CREB activation (e.g., calcium- and/or calmodulinstimulated kinases) can compensate for AC8 loss in these regions.

AC8 is most highly expressed in the olfactory bulb, yet AC8 KO mice exhibit no alteration in odorant sensing or the ability to associate an odorant with an aversive stimulus. Why does global AC8 loss manifest a phenotype most reflective of abnormal func- 
$\mathbf{A}$

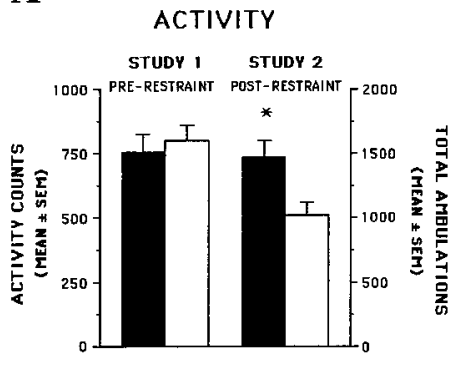

B

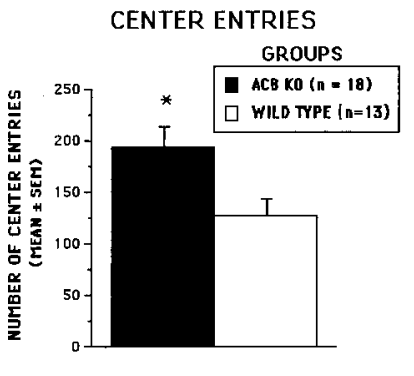

C

CENTER DISTANCE

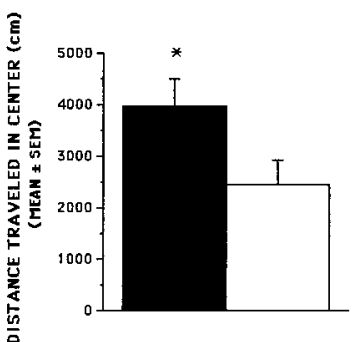

Figure 9. Analysis of open-field behavior. $A$, In study 1 before being restrained or tested on the plus-maze, the AC8 KO $(n=17)$ and $\mathrm{WT}(n=14)$ mice were screened on a $1 \mathrm{hr}$ general locomotor activity test using an open field containing relatively low photobeam resolution capabilities. Under these conditions, no differences were found between the groups for locomotor activity. In study 2 , the mice were evaluated on a $1 \mathrm{hr}$ open-field test using a high-resolution photobeam system after they had been subjected to the restraint/plus-maze test sessions. Under these conditions, the AC8 KO mice $(n=$ 18 ) were found to be significantly $\left(^{*}\right)$ more active in the numbers of ambulations than were the WT mice $(n=13)\left[F_{(1,29)}=5.67 ; p=0.024\right]$. $B, C$, The KO mice also made significantly more entries into the center area $\left[F_{(1,29)}=5.69 ; p=0.024\right]$ of the open field $(B)$ and traveled a significantly greater distance $\left[F_{(1,29)}=4.32 ; p=0.047\right]$ in the center area $(C)$ compared with the WT mice.

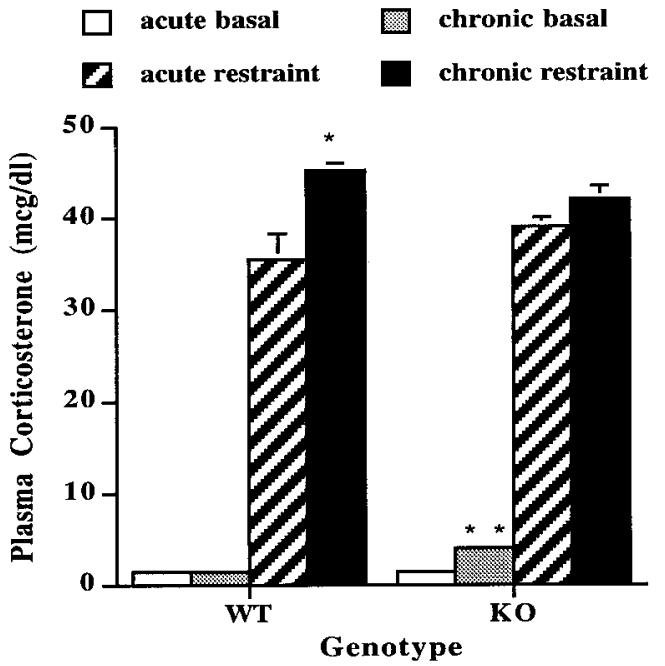

Figure 10. Adrenal response to restraint stress in AC8 KO mice. AC8 $\mathrm{KO}$ and WT adult male mice ( $n=3-4$ per group) underwent retroorbital phlebotomy for plasma corticosterone measurement before any restraint (acute basal), after one episode of $1 \mathrm{hr}$ of restraint (acute restraint), before a seventh episode of $1 \mathrm{hr}$ per day of restraint (chronic basal), or immediately after a seventh episode of $1 \mathrm{hr}$ per day of restraint (chronic restraint). Data are presented as the mean \pm SEM. * $p<0.05$ versus WT acute restraint; ${ }^{* *}, p<0.01$ versus $\mathrm{KO}$ acute basal, or $p<0.05$ versus WT acute and chronic basal.

tion in the CA1 region, and what can this teach us about the stress response? The hippocampus and notably its CA1 region possess the highest concentration of type II glucocorticoid receptors in the brain (McEwen et al., 1986; Van Eekelen et al., 1988; Stumpf et al., 1989). It is these lower affinity glucocorticoid receptors that undergo occupation specifically during stress-associated glucocorticoid increases, as opposed to at basal glucocorticoid concentrations (Jacobson and Sapolsky, 1991). Furthermore, exogenous glucocorticoid administration, as well as changes in endogenous glucocorticoid after stress, increase the induction of LTD in the CA1 region (Xu et al., 1998) by action on type II glucocorticoid receptors. This action of glucocorticoid on hippocampal neurons for induction of LTD requires new protein synthesis (Xu et al., 1998), with important physiological sequelae including increased $\mathrm{Ca}^{2+}$ action potentials and voltage-activated $\mathrm{Ca}^{2+}$ currents (Kerr et al., 1992). We postulate that the CA1 region provides a

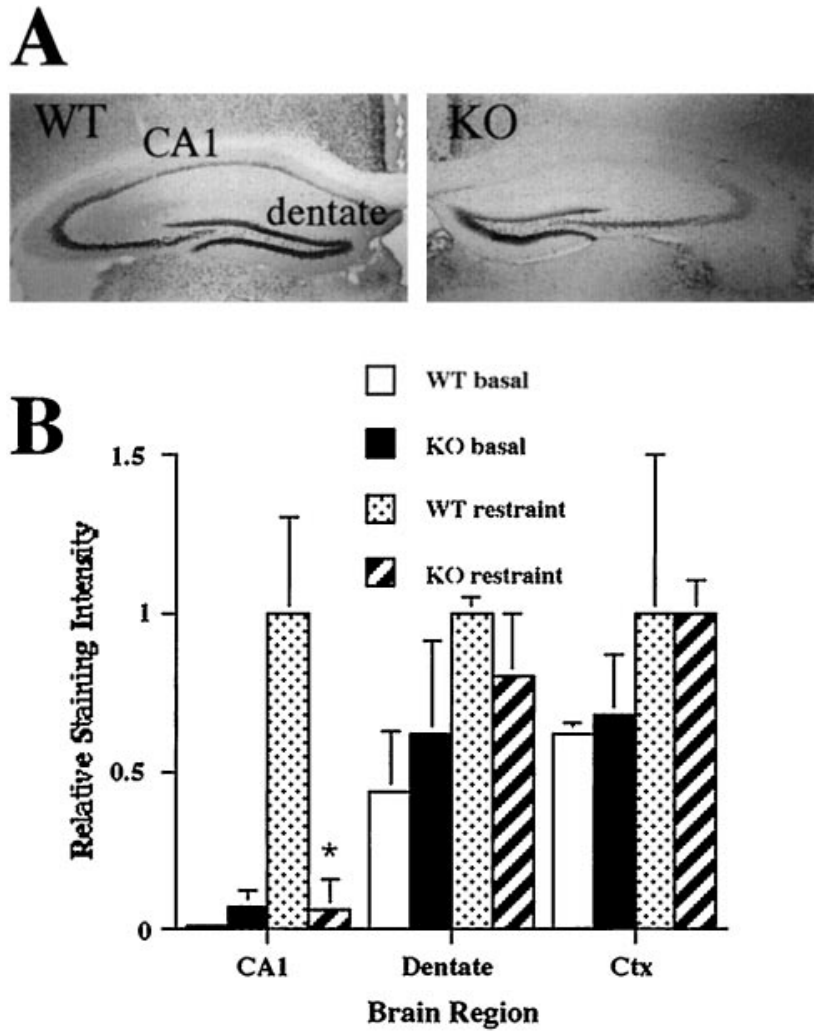

Figure 11. pCREB immunohistochemistry in AC8 KO and WT mice. $A$, Representative sections through the hippocampus of AC8 KO (right) and WT (left) mice $2 \mathrm{hr}$ after restraint stress stained with a pCREB antibody. Positive cells are demonstrated by deposition of a dark nuclear precipitate after peroxidase staining. A specific deficit in pCREB immunoreactivity is seen in the CA1 region of the hippocampus of the AC8 KO mice, whereas cortex and dentate gyrus show no difference from WT. B, Quantitation of pCREB immunohistochemistry. Densitometric analysis of sections from $n=3 \mathrm{WT}$ and $\mathrm{KO}$ mice per treatment (basal or $2 \mathrm{hr}$ after restraint) is shown. The average density of the WT postrestraint group is normalized to 1 for each brain region. * $p<0.05$ versus WT CA1. Ctx, Cortex.

unique site for integrating changes in serum and CNS glucocorticoids arising during the response to stress with calciummediated changes in CREB activation. Our data in AC8 KO mice implicate AC8 as a critical molecule for the translation of in- 
creased intracellular calcium to altered protein kinase A and/or CREB-mediated changes in gene expression that impact upon induction of LTD and the response to stress. The altered response to chronic stress observed in the AC8 KO mice, together with an absence of other significant consequences of loss of AC8 activity, implicates pharmacological modulation of AC8 action as a possible therapeutic intervention for stress-related disorders.

\section{REFERENCES}

Brandon EP, Zhuo M, Huang Y-Y, Qi M, Gerhold KA, Burton KA, Kandel ER, McKnight GS, Idzerda RL (1995) Hippocampal longterm depression and depotentiation are defective in mice carrying a targeted disruption of the gene encoding the RI $\beta$ subunit of cAMPdependent protein kinase. Proc Natl Acad Sci USA 92:8851-8855.

Brooks SP, Storey KB (1992) Bound and determined: a computer program for making buffers of defined ion concentrations. Anal Biochem 201:119-126.

Brosnan-Watters G, Wozniak DF, Nardi A, Olney JW (1996) Acute behavioral effects of MK-801 in the mouse. Pharmacol Biochem Behav 53:701-711.

Brosnan-Watters G, Wozniak DF, Nardi A, Olney JW (1999) Parallel recovery of MK-801-induced spatial learning impairment and neuronal injury in male mice. Pharmacol Biochem Behav 62:111-122.

Cali JJ, Zwaagstra JC, Mons N, Cooper DM, Krupinski J (1994) Type VIII adenylyl cyclase. A Ca2+/calmodulin-stimulated enzyme expressed in discrete regions of rat brain. J Biol Chem 269:12190-12195.

Chiesa R, Piccardo P, Ghetti B, Harris DA (1998) Neurological illness in transgenic mice expressing a prion protein with an insertional mutation. Neuron 21:1339-1351.

Chrousos GP (1995) The hypothalamic-pituitary-adrenal axis and immune-mediated inflammation. N Engl J Med 332:1351-1362.

Chrousos GP, Gold PW (1992) The concepts of stress and stress system disorders. JAMA 267:1244-1252.

Cooper DM, Mons N, Karpen JW (1995) Adenylyl cyclases and the interaction between calcium and cAMP signalling. Nature 374:421-424.

Dudek SM, Bear MF (1992) Homosynaptic long-term depression in area CA1 of hippocampus and effects of $N$-methyl-D-aspartate receptor blockade. Proc Natl Acad Sci USA 89:4363-4367.

Espejo EF (1997) Effects of weekly or daily exposure to the elevated plus-maze in male mice. Behav Brain Res 87:233-238.

Gorman AL, Dunn AJ (1993) Beta-adrenergic receptors are involved in stress-related behavioral changes. Pharmacol Biochem Behav 45:1-7.

Grailhe R, Waeber C, Dulawa SC, Hornung JP, Zhuang X, Brunner D, Geyer M, Hen R (1999) Increased exploratory activity and altered response to LSD in mice lacking the 5-HT5A receptor. Neuron 22:581-591.

Griff IC, Reed RR (1995) The genetic basis for specific anosmia to isovaleric acid in the mouse. Cell 83:407-414.

Hill HD, Straka JG (1988) Protein determination using bicinchoninic acid in the presence of sulfhydryl reagents. Anal Biochem 170:203-208.

Huang LQ, Rowan MJ, Anwyl R (1999) Role of protein kinases A and $\mathrm{C}$ in the induction of mGluR-dependent long-term depression in the medial perforant path of the rat dentate gyrus in vitro. Neurosci Lett 274:71-74.

Jacobson L, Sapolsky R (1991) The role of the hippocampus in feedback regulation of the hypothalamic-pituitary-adrenocortical axis. Endocr Rev 12:118-134.

Kerr DS, Campbell LW, Thibault O, Landfield PW (1992) Hippocampal glucocorticoid receptor activation enhances voltage-dependent $\mathrm{Ca} 2+$ conductances: relevance to brain aging. Proc Natl Acad Sci USA 89:8527-8531.

Kim JJ, Foy MR, Thompson RF (1996) Behavioral stress modifies hippocampal plasticity through $N$-methyl-D-aspartate receptor activation. Proc Natl Acad Sci USA 93:4750-4753.

Lister RG (1987) The use of a plus-maze to measure anxiety in the mouse. Psychopharmacology (Berl) 92:180-185.

Manahan-Vaughan D, Braunewell K-H (1999) Novelty acquisition is associated with induction of hippocampal long-term depression. Proc Natl Acad Sci USA 96:8739-8744.

Matsuoka I, Maldonado R, Defer N, Noel F, Hanoune J, Roques BP (1994) Chronic morphine administration causes region-specific increase of brain type VIII adenylyl cyclase mRNA. Eur J Pharmacol 268:215-221.
McEwen BS (1998a) Protective and damaging effects of stress mediators. N Engl J Med 338:171-179.

McEwen BS (1998b) Stress, adaptation, and disease. Allostasis and allostatic load. Ann NY Acad Sci 840:33-44.

McEwen BS, Stellar E (1993) Stress and the individual: mechanisms leading to disease. Arch Intern Med 153:2093-2101.

McEwen BS, de Kloet ER, Rostene W (1986) Adrenal steroid receptors and actions in the nervous system. Physiol Rev 66:1121-1188.

Muglia L, Jacobson L, Dikkes P, Majzoub JA (1995) Corticotropinreleasing hormone deficiency reveals major fetal but not adult glucocorticoid need. Nature 373:427-432.

Muglia LJ, Jenkins NA, Gilbert DJ, Copeland NG, Majzoub JA (1994) Expression of the mouse corticotropin-releasing hormone gene in vivo and targeted inactivation in embryonic stem cells. J Clin Invest 93:2066-2072.

Muglia LM, Schaefer ML, Vogt SK, Gurtner G, Imamura A, Muglia LJ (1999) The 5'-flanking region of the mouse adenylyl cyclase type VIII gene imparts tissue-specific expression in transgenic mice. J Neurosci 19:2051-2058.

Nagy A, Rossant J, Nagy R, Abramow-Newerly W, Roder JC (1993) Derivation of completely cell culture-derived mice from early-passage embryonic stem cells. Proc Natl Acad Sci USA 90:8424-8428.

Potter E, Sutton S, Donaldson C, Chen R, Perrin M, Lewis K, Sawchenko PE, Vale W (1994) Distribution of corticotropin-releasing factor receptor mRNA expression in the rat brain and pituitary. Proc Natl Acad Sci USA 91:8777-8781.

Qi M, Zhuo M, Skalhegg BS, Brandon EP, Kandel ER, McKnight GS, Idzerda RL (1996) Impaired hippocampal plasticity in mice lacking the $\mathrm{C} \beta_{1}$ catalytic subunit of cAMP-dependent protein kinase. Proc Natl Acad Sci USA 93:1571-1576.

Ramboz S, Oosting R, Amara DA, Kung HF, Blier P, Mendelsohn M, Mann JJ, Brunner D, Hen R (1998) Serotonin receptor 1A knockout: an animal model of anxiety-related disorder. Proc Natl Acad Sci USA 95:14476-14481.

Rodgers RJ, Cole JC (1993) Influence of social isolation, gender, strain, and prior novelty on plus-maze behaviour in mice. Physiol Behav 54:729-736.

Rodgers RJ, Shepherd JK (1993) Influence of prior maze experience on behaviour and response to diazepam in the elevated plus-maze and light/dark tests of anxiety in mice. Psychopharmacology (Berl) 113:237-242.

Rodgers RJ, Lee C, Shepherd JK (1992) Effects of diazepam on behavioural and antinociceptive responses to the elevated plus-maze in male mice depend upon treatment regimen and prior maze experience. Psychopharmacology (Berl) 106:102-110.

Rodgers RJ, Johnson NJT, Carr J, Hodgson TP (1997) Resistance of experientially-induced changes in murine plus-maze behaviour related to altered retest conditions. Behav Brain Res 86:71-77.

Salomon Y, Londos C, Rodbell M (1974) A highly sensitive adenylyl cyclase assay. Anal Biochem 58:541-548.

Sawchenko PE, Brown ER, Chan RK, Ericsson A, Li HY, Roland BL, Kovacs KJ (1996) The paraventricular nucleus of the hypothalamus and the functional neuroanatomy of the visceromotor responses to stress. Prog Brain Res 107:201-222.

Smith GW, Aubry J-M, Dellu F, Contarino A, Bilezikjian LM, Gold LH, Chen R, Marchuk Y, Hauser C, Bentley CA, Sawchenko PE, Koob GF, Vale W, Lee K-F (1998) Corticotropin-releasing factor receptor 1-deficient mice display decreased anxiety, impaired stress response, and aberrant neuroendocrine development. Neuron 20:1093-1102.

Storm DR, Hansel C, Hacker B, Parent A, Linden DJ (1998) Impaired cerebellar long-term potentiation in type I adenylyl cyclase mutant mice. Neuron 20:1199-1210.

Stumpf WE, Heiss C, Sar M, Duncan GE, Craver C (1989) Dexamethasone and corticosterone receptor sites: differential topographic distribution in rat hippocampus revealed by high resolution autoradiography. Histochemistry 92:201-210.

Sunahara RK, Dessauer CW, Gilman AG (1996) Complexity and diversity of mammalian adenylyl cyclases. Annu Rev Pharmacol Toxicol 36:461-480.

Tronche F, Kellendonk C, Kretz O, Gass P, Anlag K, Orban PC, Bock R, Klein R, Schutz G (1999) Disruption of the glucocorticoid receptor gene in the nervous system results in reduced anxiety. Nat Genet 23:99-103.

Tybulewicz V, Crawford C, Jackson P, Bronson R, Mulligan R (1991) 
Neonatal lethality and lymphopenia in mice with a homozygous disruption of the c-abl proto-oncogene. Cell 65:1153-1163.

Tzounopoulos T, Janz R, Sudhof TC, Nicoll RA, Malenka RC (1998) A role for cAMP in long-term depression at hippocampal mossy fiber synapses. Neuron 21:837-845.

Van Eekelen JAM, Jiang W, de Kloet ER, Bohn MC (1988) Distribution of the mineralocorticoid and the glucocorticoid receptor mRNAs in the rat hippocampus. J Neurosci Res 21:88-94.

Villacres EC, Wu Z, Hua W, Nielsen MD, Watters JJ, Yan C, Beavo J, Storm DR (1995) Developmentally expressed $\mathrm{Ca}(2+)$-sensitive adenylyl cyclase activity is disrupted in the brains of type I adenylyl cyclase mutant mice. J Biol Chem 270:14352-14357.

Wong ST, Athos J, Figueroa XA, Pineda VV, Schaefer ML, Chavkin CC, Muglia LJ, Storm DR (1999) Calcium-stimulated adenylyl cyclase activity is critical for hippocampus-dependent long-term memory and late phase LTP. Neuron 23:787-798.

Wozniak DF, Olney JW, Kettinger LD, Price M, Miller JP (1990) Behavioral effects of MK-801 in the rat. Psychopharmacology (Berl) 101:47-56.
Wu ZL, Thomas SA, Villacres EC, Xia Z, Simmons ML, Chavkin C, Palmiter RD, Storm DR (1995) Altered behavior and long-term potentiation in type I adenylyl cyclase mutant mice. Proc Natl Acad Sci USA 92:220-224.

Xia Z, Refsdal CD, Merchant KM, Dorsa DM, Storm DR (1991) Distinct patterns for the distribution of mRNA for the calmodulinsensitive adenylyl cyclase in rat brain: expression in areas associated with learning and memory. Neuron 6:431-443.

Xu L, Anwyl R, Rowan MJ (1997) Behavioral stress facilitates the induction of long-term depression in the hippocampus. Nature 387:497-500.

Xu L, Holscher C, Anwyl R, Rowan MJ (1998) Glucocorticoid receptor and protein/RNA synthesis-dependent mechanisms underlie the control of synaptic plasticity by stress. Proc Natl Acad Sci USA 95:3204-3208.

Zhuo M, Zhang W, Son H, Mansuy I, Sobel RA, Seidman J, Kandel ER (1999) A selective role of calcineurin A $\alpha$ in synaptic depotentiation in hippocampus. Proc Natl Acad Sci USA 96:4650-4655. 